\title{
Will COVID-19 Vaccination Be Successful Without Social Distancing? A Simulation of an Outbreak in Sri Lanka
}

\author{
International Journal of Infectious Diseases and Research
}

Research Article

\author{
NWANY Wijesekara ${ }^{1 *}$, HDB Herath, KALC Kodithuwakku and BAMP Bulathsinghe \\ *Correspondence author \\ NWANY Wijesekara \\ ${ }^{1}$ Disaster Preparedness and Response Division, Ministry of \\ Health, Sri Lanka \\ Disaster Preparedness and Response Division \\ Ministry of Health \\ Sri Lanka
}

Submitted : 14 Dec 2020 ; Published : 13 Jan 2021

\begin{abstract}
Coronavirus disease (COVID-19) pandemic is causing morbidity, mortality and economic damage in an unprecedented manner across the world. Many non-pharmacological interventions such as restricting community mobility, social distancing, handwashing and face mask use have been carried out to prevent COVID-19. Promising vaccine results and their approval for emergency use in some countries has created much interest in their use as the ultimate solution to control the outbreak at global level, Sri Lanka being no exception. Objective of this study was to compare the success of a COVID-19 vaccination with or without social distancing during a simulated outbreak of widespread transmission of COVID-19 in Sri Lanka. The beta version of the online application of the mathematical model developed by the London School of Tropical Medicine and Hygiene using the Susceptible, Exposed, Infected and Removed Model was used for the simulation. The results show that COVID-19 vaccination in Sri Lanka without social distancing is unlikely to reduce case number, symptomatic admissions or deaths. In the absence of social distancing, making vaccines available earlier, faster or in increased quantities will not contribute to any meaningful reduction of the disease outcomes. The continued adherence to social distancing is recommended for any benefits of vaccination to be meaningful.
\end{abstract}

Keywords: COVID-19, Social Distancing, COVID-19 Vaccine, SEIR Model, Simulation

\section{Introduction}

Coronavirus disease (COVID-19) is an infectious disease of which the etiological agent is a newly discovered coronavirus from Wuhan, China in 2019 [1]. The massive impact of the Coronavirus disease (COVID-19) pandemic is evident with $70,228,447$ confirmed cases including 1,595,187 deaths, being reported to the World Health Organization (WHO) as per 13 December 2020 [2]. As a result of the COVID-19 pandemic, it is forecasted that the global Gross Domestic Product (GDP) will contract by $5.2 \%$ and the economies will be left with lasting scars, despite the mitigatory efforts by governments across the world [3].

Non-pharmaceutical interventions such as restriction of public events, school closure and social distancing targeting the prevention the spread of COVID-19 have been advocated and promoted $[4,5]$. In addition, hand hygiene, respiratory etiquette and use of face mask have been used as interventions to prevent the spread of the disease [6].

However, a COVID-19 vaccine has been much anticipated as the magic bullet against this pandemic. As per 10.12.2020, 52 candidate vaccines are in clinical evaluation [7, 8]. Vaccine by Pfizer and BioNTech is claimed to be more than 95\% effective [9]. Moderna vaccine is claimed to protect $94.5 \%$ people $[10,11]$.
The Oxford University / AstraZeneca vaccine has been shown to stop 70\% people developing COVID-19 symptoms [12]. More affluent countries are investing in vaccine development and claim their access to vaccines, as soon as they will be available [13]. In the meantime, COVAX, an initiative coordinated by Gavi, the Vaccine Alliance, the Coalition for Epidemic Preparedness Innovations (CEPI) and the $\mathrm{WHO}$, is coordinating efforts in ensuring access to vaccine of all participating countries, irrespective of their income level [14]. The government of Sri Lanka too has expressed its commitment to ensure the availability of the vaccine to its population, the Minister of Health of Sri Lanka declaring the efforts to make the vaccine available to $20 \%$ of the population initially amounting to 4.2 million doses through the COVAX facility [15].

Both governments and the community members are experiencing fatigue of stringent interventions implemented and sustained in unprecedented manner against the prevention of COVID-19 [16]. In this context, the arrival of a vaccine could be seen as a muchawaited relief. However, if the non-pharmacological measures are loosened too early, the anticipated benefit from the vaccine, as well as the sacrifice made by governments and public so far may be lost. In this context, it is important to understand how the 
COVID-19 vaccination and non-pharmacological interventions, specifically social distancing could interact synergistically towards COVID-19 outbreak control. The objective of this study was to compare the success of a COVID-19 vaccination with or without social distancing in Sri Lanka.

\section{Methodology}

Mathematical models provide the opportunity for researchers, policy makers and implementers to understand complex public health problems [17]. In addition, they could also be used to test different public health solutions in safe environments which would not have been possible in real world, due to practical, logistic and ethical reasons (Kretzschmar 2020). Several mathematical models have been used across the world, both to predict the Covid-19 outbreak, as well as to explore the effects of different interventions on its progress [18-21].

The London School of Hygiene and Tropical Medicine (LSHTM) COVID-19 Transmission App (beta version 2) uses an agestructured mathematical model which can simulate COVID-19 transmission in a population [22]. Above model, using a compartmental model assumes that susceptible people who get infected with COVID-19 can either develop clinical symptoms through pre-clinical stage (clinical infections), while the others would only develop mild or no symptoms (subclinical infections) which will go unnoticed. Both clinical and subclinical infections could either end up in recovery, isolation or death [23, 24].

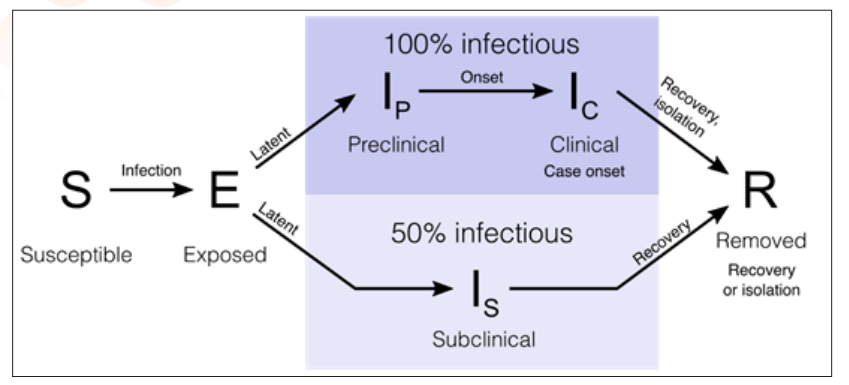

Figure 1: Susceptible, Exposed, Infected and Recovered Model used in the LSHTP COVID-19 Model

Source: Davies et al, 2020

The model also assumes children to be less susceptible to infection, and less likely to demonstrate clinical symptoms compared to the adults [22, 23]. Contract matrices developed by previous studies have been used for the simulation of the transmission in the model used by this app [25, 26].

We used the LSHTM COVID-19 Transmission App (beta version 2) for the simulation. We selected the model parameters for Sri Lanka as follows.

\begin{tabular}{|l|l|}
\hline Model input & Variable \\
\hline Country & Sri Lanka \\
\hline Epidemic start date & 01.09 .2020 \\
\hline Starting number of infections & 01 \\
\hline Basic Reproduction number & 2.1 \\
\hline Proportion immune at start & 0 \\
\hline Latent period & 3 days \\
\hline Pre-clinical period & 2.1 days \\
\hline Clinical period & 2.9 days \\
\hline Subclinical period & 5 days \\
\hline Date of the first case & 04.10 .2020 \\
\hline Number of cases on the first date & 1 \\
\hline
\end{tabular}

Table 1: Model Inputs

According to WHO, even though Sri Lanka is not in community transmission as per 13.12.2020, for the simulation purposes we assumed the current wave to be the beginning of an outbreak of widespread community transmission in Sri Lanka. This wave was detected 04.10.2020, and examining the epidemiological curve shows that the first case would have occurred around 01.09.2020 [27]. Hence, the first case of the current outbreak was taken as 01.09.2020. Since the number of COVID-19 cases occurring before 01.09.2020 is quite small in comparison to the number reported thereafter, it is justifiable to take this point as the commencement of the outbreakof widespread community transmission for the simulation purposes. Since social distancing measures were implemented as soon as this large number of cases was detected, the date of commencement of social distancing was taken as 04.10.2020. The model was run for a period of 365 days.

We considered the above trend as first and the baseline scenario, and named it as S0V0. In addition, we developed nine mitigatory scenarios. Social distancing was taken yes or no, yes meaning $50 \%$ social distancing. The value of $50 \%$ social distancing was an arbitrary value, however, anything more than $50 \%$ of social distancing seemed impossible as per the consensus of the research team on their observation of the public behavior in Sri Lanka. The $50 \%$ social distancing was assumed to be continued until the end of the simulation period, for the models which had a social distancing element.

Different COVID-19 vaccination scenarios were developed taking several aspects into consideration. The time of commencement of the vaccination campaign had two options: in January or in March. The duration of the vaccination program could have two options: three months or six months. The government of Sri Lanka has claimed to obtain 4.2 million doses covering $20 \%$ of the population. For the simulation purposes, we rounded it off to 4.5 million doses. The ten scenarios that we simulated are given in Table 2. 


\begin{tabular}{|c|c|c|}
\hline Scenario & Scenario Code & Mitigation Scenario \\
\hline 1 & S0V0 & No Mitigation \\
\hline 2 & S1V0 & Social distancing only \\
\hline 3 & S0V1 & $\begin{array}{l}\text { 4.5 Million Vaccinations done } \\
\text { over } 6 \text { months starting in January } \\
2021\end{array}$ \\
\hline 4 & S0V2 & $\begin{array}{l}\text { 4.5 Million Vaccinations done } \\
\text { over } 3 \text { months starting in January } \\
2021\end{array}$ \\
\hline 5 & S0V3 & $\begin{array}{l}\text { 4.5 Million Vaccinations done } \\
\text { over } 6 \text { months starting in March } \\
2021\end{array}$ \\
\hline 6 & S0V4 & $\begin{array}{l}\text { 4.5 Million Vaccinations done } \\
\text { over } 3 \text { months starting in March } \\
2021\end{array}$ \\
\hline 7 & S1V1 & $\begin{array}{l}\text { Social distancing with distribution } \\
\text { of } 4.5 \text { Million Vaccinations done } \\
\text { over } 6 \text { months starting in January } \\
2021\end{array}$ \\
\hline 8 & $\mathrm{~S} 1 \mathrm{~V} 2$ & $\begin{array}{l}\text { Social distancing with distribution } \\
\text { of } 4.5 \text { Million Vaccinations done } \\
\text { over } 6 \text { months starting in March } \\
2021\end{array}$ \\
\hline 9 & S1V3 & $\begin{array}{l}\text { Social distancing with distribution } \\
\text { of } 4.5 \text { Million Vaccinations done } \\
\text { over } 3 \text { months starting in January } \\
2021\end{array}$ \\
\hline 10 & S1V4 & $\begin{array}{l}\text { Social distancing with distribution } \\
\text { of } 4.5 \text { Million Vaccinations done } \\
\text { over } 3 \text { months starting in March } \\
2021\end{array}$ \\
\hline
\end{tabular}

Table 2: Mitigation Scenarios

Subsequently we ran the simulation, doubling the number of doses at 9 million doses. The epidemiological curve for different mitigatory scenarios were developed, and were compared with the baseline scenario. The total number of cases, total number of symptomatic admissions, and total number of deaths under different mitigatory scenarios were calculated. In addition, the difference between the total number of cases, total number of symptomatic admissions, and total number of deaths between the baseline scenario and other scenarios, as well as the proportion thereof were calculated.

\section{Results}

Figure 2 and Table 3 shows the summary of the models as per the ten scenarios considered.

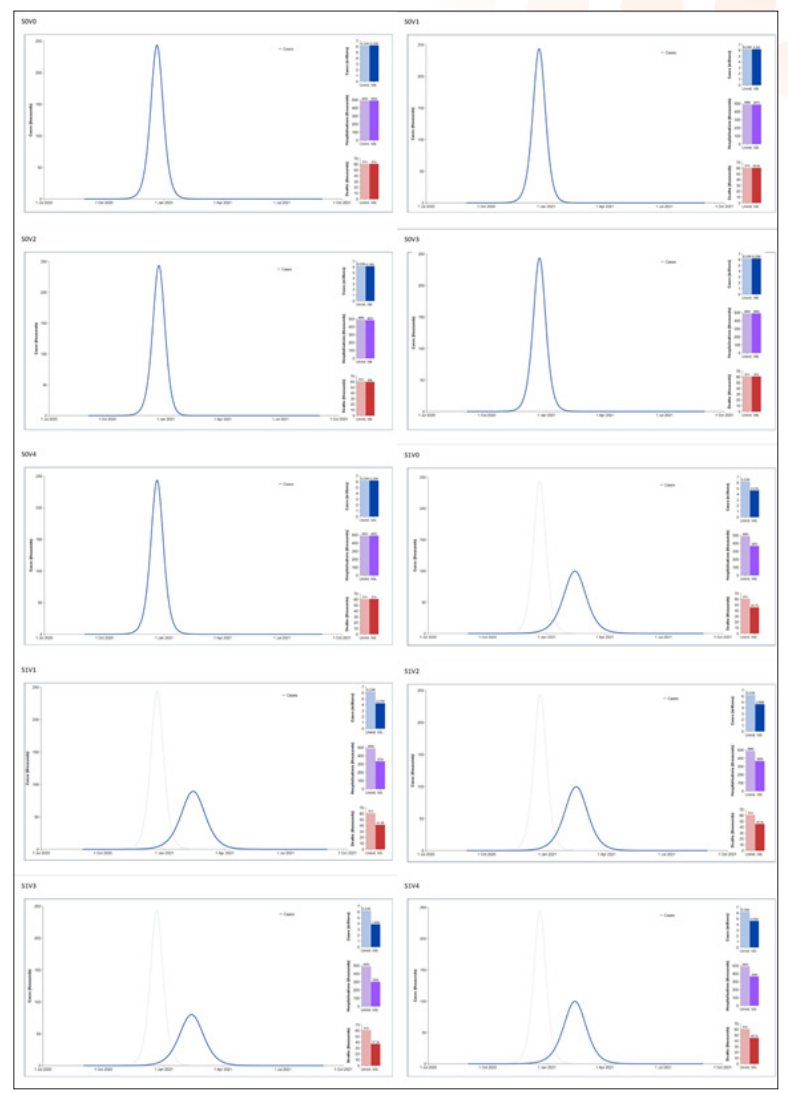

Figure 2: Outbreak Curves Under Ten Mitigatory Scenarios

\begin{tabular}{|l|l|l|l|l|l|l|l|l|l|}
\hline $\begin{array}{l}\text { Scenario } \\
\text { Code }\end{array}$ & $\begin{array}{l}\text { Number } \\
\text { of Cases } \\
\text { (Millions) }\end{array}$ & $\begin{array}{l}\text { Reduction } \\
\text { of } \\
\text { Number } \\
\text { of Cases } \\
\text { (Millions) }\end{array}$ & $\begin{array}{l}\text { Percentage } \\
\text { Reduction } \\
\text { of Cases }\end{array}$ & $\begin{array}{l}\text { Number of } \\
\text { Symptomatic } \\
\text { Admissions } \\
\text { (Thousands) }\end{array}$ & $\begin{array}{l}\text { Reduction of } \\
\text { Number of } \\
\text { Symptomatic } \\
\text { Admission } \\
\text { (Thousands) }\end{array}$ & $\begin{array}{l}\text { Percentage } \\
\text { Reduction of } \\
\text { Symptomatic } \\
\text { Admission }\end{array}$ & $\begin{array}{l}\text { Number } \\
\text { of Deaths } \\
\text { (Thousands) }\end{array}$ & $\begin{array}{l}\text { Reduction } \\
\text { of Number } \\
\text { of Deaths }\end{array}$ & $\begin{array}{l}\text { Percentage } \\
\text { Reduction } \\
\text { of Deaths } \\
\text { Percentage }\end{array}$ \\
\hline S0V0 & 6.23 & 0.00 & 0.0 & 490 & 0 & 0.0 & 61.0 & 0.0 & 0.0 \\
\hline S1V0 & 4.67 & 1.56 & 25.0 & 367 & 123 & 33.5 & 45.7 & 15.3 & 33.5 \\
\hline S0V1 & 6.20 & 0.03 & 0.5 & 487 & 3 & 0.6 & 60.6 & 0.4 & 0.7 \\
\hline S0V2 & 6.16 & 0.07 & 1.1 & 482 & 8 & 1.7 & 60.0 & 1.0 & 1.7 \\
\hline S0V3 & 6.23 & 0.00 & 0.0 & 490 & 0 & 0.0 & 61.0 & 0.0 & 0.0 \\
\hline S0V4 & 6.23 & 0.00 & 0.0 & 490 & 0 & 157 & 47.1 & 41.4 & 19.0 \\
\hline S1V1 & 4.27 & 1.96 & 31.5 & 333 & 125 & 34.2 & 45.5 & 15.5 & 34.0 \\
\hline S1V2 & 4.65 & 1.58 & 25.4 & 365 & 190 & 63.3 & 37.3 & 23.7 & 63.5 \\
\hline S1V3 & 3.88 & 2.35 & 37.7 & 300 & 126 & 34.6 & 45.3 & 15.7 & 34.7 \\
\hline S1V4 & 4.63 & 1.60 & 25.7 & 364 & & & & \\
\hline
\end{tabular}

Table 3: Distribution of Cases. Symptomatic Cases and Deaths under Ten Mitigatory Scenarios 
As per the baseline model SOVO, it is predicted that there will be 6.23 million cases, with 490 thousand symptomatic cases being admitted. The number of deaths is predicted to be 61 thousand.

The S1V0 model encompasses 50\% social distancing occurring from 04.10.2020 onwards, as the only intervention. Under this model scenario, the total number of cases will be 4.67 million, with 367 thousand symptomatic admissions, and 45.7 thousand deaths. It should be noted that compared to the baseline scenario, social distancing alone could provide the benefit of reduction of $25 \%$ of the cases, $33.5 \%$ of symptomatic admissions and $33.5 \%$ cases respectively.

Four scenarios modelled vaccination campaigns as the only mitigatory measure, each varying in their timing and duration. The highest percentage reduction of the cases, number of symptomatic admissions and deaths under above four vaccines only mitigatory scenarios were $1.1 \%, 1.7 \%$ and $1.7 \%$ respectively, which was for scenario SOV1 which demanded 4.5 million vaccinations to be given commencing from 01.01.2020 over a period of three months.

S1V1 to S1V4 mitigatory scenarios tested out social distancing coupled with the same vaccination scenarios considered above. It could be seen that percentage reductions in cases, symptomatic admissions and deaths, all increased with the combination of social distancing with four different combinations of vaccination campaigns. However, the highest percentage reduction was observed for S1V3 which demands for the administration of 4.5 million vaccines within three months commencing from January 2020. In contrast, if the same amounts of vaccines to be administered over the same period, three months later, that means starting from March, the percentage reductions would decrease considerably: Reduction of percentage of cases from $37.7 \%$ to $25.7 \%$; symptomatic admissions from $63.3 \%$ to $37.3 \%$, and deaths from $63.5 \%$ to $34.7 \%$.

Next, we wanted to see the effects of doubling the vaccine amount provided on the outbreak dynamics.

As evident from Figure $4-6$, doubling the number of vaccine doses does not seem to have any considerable effect on the number of cases, symptomatic admissions or deaths without social distancing. If the number of vaccine doses are doubled in January along with social distancing, cases, symptomatic admissions and deaths seem to be reducing, whereas if the same is done in March, the reduction of the same are not markedly different.

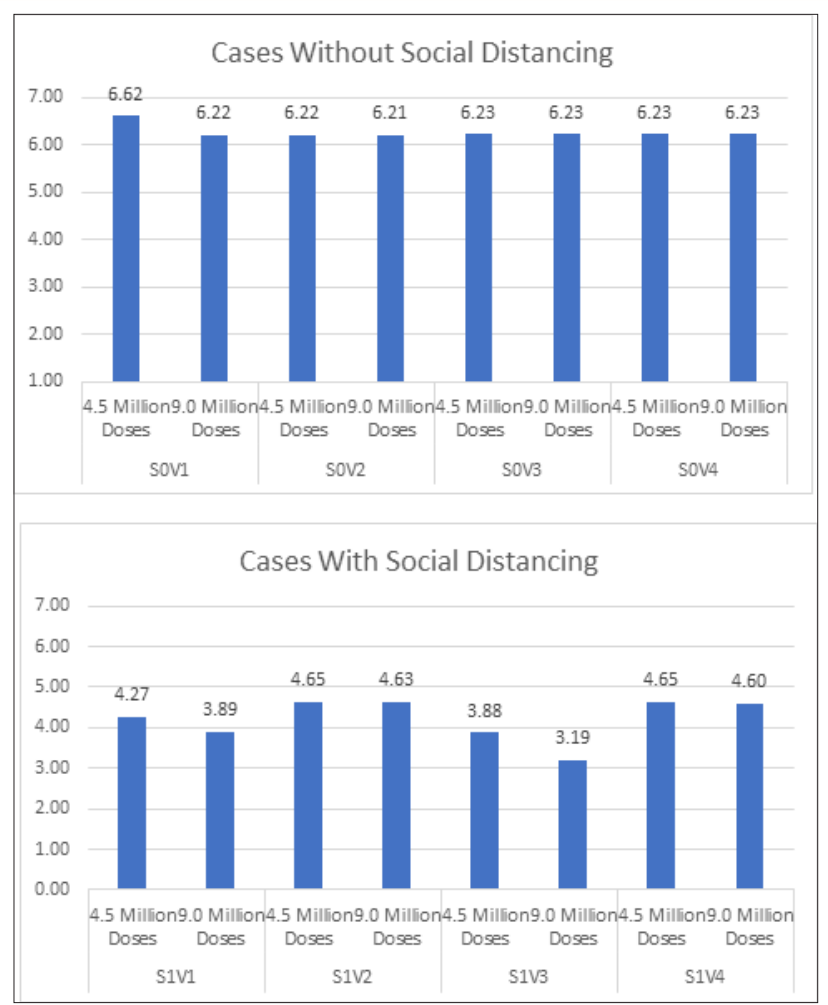

Figure 3: Effects of Doubling of Vaccination Doses on Cases

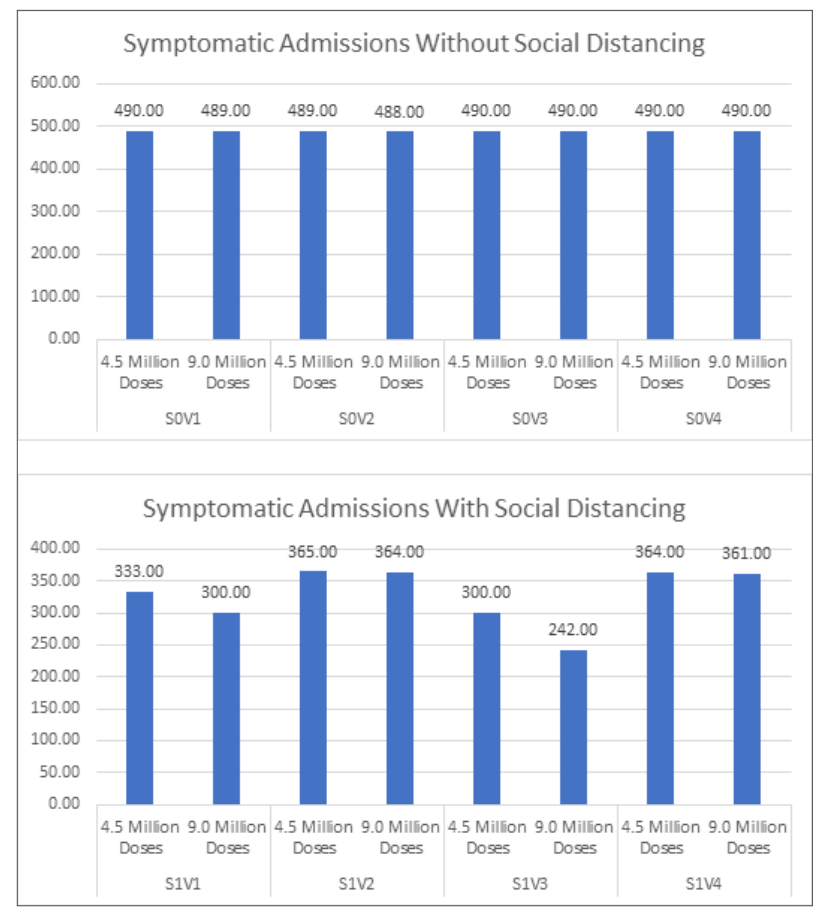

Figure 4: Effects of Doubling of Vaccination Doses on Symptomatic Admissions 


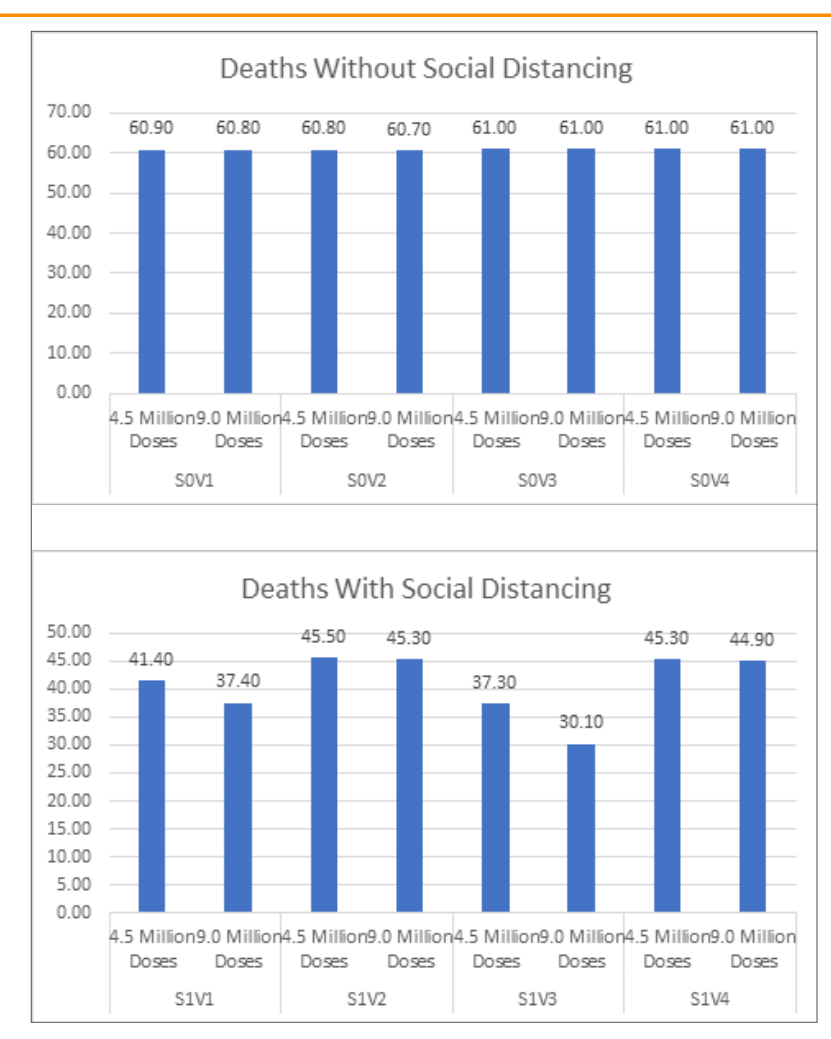

Figure 5: Effects of Doubling of Vaccination Doses on Deaths

\section{Conclusion}

In summary, social distancing seems to be playing a decisive role in determining how different vaccination scenarios would work. In addition, earlier the vaccines are available, it seems to be reducing more cases, symptomatic admissions as well as deaths. Further, faster immunization campaigns tend to have larger reductions of cases, symptomatic admissions and deaths. Increasing vaccine number seems to be affecting the number of cases, symptomatic admissions and deaths, only if the vaccination program is carried out in combination with social distancing and earlier in the epidemiological curve.

\section{Discussion}

COVID-19 is a complex public health problem which has multiple dimensions, both to the problem itself, as well as to its solutions. Non-pharmacological interventions such as social distancing have contributed to the prevention of the COVID-19 pandemic. However, the COVID-19 vaccine has been looked up to as the magic bullet that will end the pandemic. Though this narrative seems to be both appealing and soothing, this does not seem to be the case for many developing countries, Sri Lanka being no exception. This country level simulation using the CMMID COVID-19 transmission app, beta version of the center for mathematical modelling of infectious diseases at the London School of Tropical Medicine and Hygiene was aimed at visualizing the effects of a selected non-pharmacological intervention, namely social distancing and vaccination, individually as well as in combination in a simulated COVID-19 outbreak in Sri Lanka [22]. At the outset, it should be made clear that the focus of this exercise was not to predict how the current COVID-19 outbreak will move forwarded in Sri Lanka. Rather, our focus was to test the effects of the two interventions on a simulated outbreak. Similar approach has been used in understanding the effects of widespread community transmission in Sri Lanka using simulations, rather than using actual case numbers[20,21].

It is very clear from the findings of the study that social distancing, at least at around 50\% can reduce the transmission of cases, symptomatic admissions and deaths in a considerable manner. In contrast, vaccination alone, under the four different scenarios, varying on their duration and the timing clearly shows that the effects of reducing the percentage reduction of cases, symptomatic admissions and deaths are quite negligible. This is an alarming finding, since vaccination is often seen as the savior from stringent measures of which both the governments and the communities are tired of.

COVID-19 vaccination carried out in combination with social distancing tends to be having an additional benefit in the reduction of cases, symptomatic admissions and deaths. It is also seen that as per the simulated scenario, earlier the vaccine is started, better it is. Under the cover of social distancing, vaccination delivered over a period of three months seems to be reducing around $7 \%$ additional cases, $16 \%$ symptomatic admissions, as well as deaths, if both campaigns are started in January. However, starting the campaigns in January 2021 is quite unlikely, given the current global trends in vaccine availability. Thus, March 2021 or a later date would be the likely scenario for Sri Lanka. Vaccination campaigns starting as late as March, irrespective of their duration seems to be not much beneficial than social distancing alone. However, as per the current simulated outbreak, the benefits that the country could get from vaccination seems to be much less, if social distancing is not practiced. While vaccine procurement, transport and distribution has direct and indirect costs involved, social distancing measures could be implemented with relatively lesser cost. Hence, non-adherence to social distancing could greatly influence the cost effectiveness of a COVID-19 vaccination programme.

While COVAX seems to an innovative and progressive step towards ensuring the access to vaccines, it does not seem to solve the issue of getting the vaccines as fast as well as in quantities that the country needs. For example, if all three vaccine candidates get regulatory clearance, Canada, Japan, the UK, and the US will have more than enough vaccines to cover their entire populations, which means they could spare some vaccines which could become potential donations[13]. Sri Lanka could engage in public health diplomacy to explore the possibility of obtaining donated vaccines from its allies, to supplement the COVAX funded vaccines.

As the last option, the government of Sri Lanka should start making allocations for vaccinations from their national budgets. It is wise to preorder at least some vaccines with the use of national health budget or the funds raised for COVID-19 response, in addition to the plans to procure the vaccines through the COVAX initiative. However, it should be kept in mind that all these arrangements are dependent on the availability of the vaccine in the market, as well as the 
buying power of the country. Again, the country could extend its health diplomacy of its allied nations to seek assistance in vaccine procurement.

In either case, the cornerstone of the findings of this simulation exercise is that vaccination without social distancing is unlikely to reduce case number, symptomatic admissions or deaths.

Further, in the absence of social distancing, making vaccines available earlier, making vaccination programs faster, and increasing the number of vaccines also will not contribute to any meaningful reduction of in the case number, symptomatic admissions or deaths. Increasing the vaccine amount will bear considerable reduction of cases, symptomatic admissions and deaths only if vaccination is carried out along with social distancing and if the vaccination is done earlier in the epidemiological curve.

The current simulation did not model in lockdowns, travel restrictions, limitations on public gatherings, work from home or school closures. These, if implemented will add definite bonus advantages in maximizing the benefits of vaccination. However, as per date, it is unlikely that neither the government nor the public would be happy with more stringent measures which were practices at the first stages of the outbreak. However, handwashing and wearing face mask still seems to provide additional benefits in curtailing the outbreak, which are quite acceptable both in the eyes of the government as well as the general public. The New Normalcy Guidelines by the Ministry of Health encompassing aforementioned measures could definitely provide additional benefits if anticipated before and throughout the vaccination process [28].

The biggest advantages of the application used in the current model is it's easy to use online interphase despite the complex mathematical modelling process behind it. In addition, the graphical display of the model inputs and outputs also makes it user friendly. However, there are some limitations of the model behind the application used during the current simulation exercise. Firstly, the model assumes that contact patterns and other human behaviors to be static during the simulation period, and except as determined by any selected interventions. Secondly, the whole country is used as the unit of simulation than simulating epidemics in different parts of the country. Thirdly, only one model trajectory for the given set of parameters is given, rather than proposing several of them without space for uncertainty. Advanced methods could be used to overcome afore mentioned limitations.

Another limitation of the study is that it assumed individuals randomly selected from the population will be allocated to receive the COVID-19 vaccine, whereas in reality, the vaccines would be allocated on a risk-based approach, at least in the initial stages, due to its relative scarcity. For example, as indicated in the WHO SAGE values framework for the allocation and prioritization of COVID-19 vaccination, in order to maximize the reduction of morbidity and mortality, all countries are expected to adhere to unform prioritization criteria when distributing the $20 \%$ of the vaccines provided through the COVAX facility. The first priority group will be the frontline health care workers, second will be other essential service workers, third will be persons with co-morbidities and after that, persons over $60-65$ years of age. Hence, these factors, which have not been modelled in during the current study need to be taken into consideration when using the results of the study [29]. Another important limitation is that the different aspects of the vaccination program have not been modelled in during the current study. For example, the type of vaccine in relation to its efficacy (full protection vs. partial protection), current seroprevalence in the community, age structure and the contact matrix, force of infection parameters for vaccinated, symptomatic and asymptomatic groups which were not considered during the present exercise need to be incorporated in future research $[23,30]$.

In summary, social distancing must be continued before and during the COVID-19 vaccination. The study findings demand a state of emergency than that of complacency for Sri Lanka, if it is to reap the benefits of the public health window of opportunity provided by the COIVD-19 vaccination proactively and progressively. The country should ensure social distancing is practiced as much as possible in anticipation of the vaccination program as well as throughout. In addition, efforts to ensure sufficient quantities of vaccines in the timely and fast manner adhering to technical and regulatory guidelines should become a top public health priority of the country.

\section{Acknowledgment}

The valuable feedback provided by Dr. T.S.R. Pieris and Dr. Chathura Edirisuriya towards the improvement of this article is acknowledged with gratitude.

\section{References}

1. WHO (2020c). "Timeline: WHO's COVID-19 Response." https://www.who.int/emergencies/diseases/novelcoronavirus-2019/interactive-timeline.

2. WHO (2020d). "WHO Coronavirus Disease (COVID-19) Dashboard." https://covid19.who.int.

3. World Bank (2020). Global Economic Prospects, Washington, DC: World Bank.

4. Chiu Nan-Chang, Hsin Chi, Yu-Lin Tai, Chun-Chih Peng, Cheng-Yin Tseng, et al. (2020). "Impact of Wearing Masks, Hand Hygiene, and Social Distancing on Influenza, Enterovirus, and All-Cause Pneumonia During the Coronavirus Pandemic: Retrospective National Epidemiological Surveillance Study." Journal of Medical Internet Research, 22: e21257.

5. Flaxman Seth, Swapnil Mishra, Axel Gandy, H Juliette, T Unwin, et al. (2020). "Estimating the Effects of NonPharmaceutical Interventions on COVID-19 in Europe." Nature, 584: 257-2561.

6. Chan Tak Kwong (2020). "Universal Masking for COVID-19: Evidence, Ethics and Recommendations." BMJ Global Health, 5: e002819.

7. Mahase Elisabeth (2020). "Covid-19: What Do We Know about the Late Stage Vaccine Candidates?" BMJ, 371: 
$\mathrm{m} 4576$.

8. WHO (2020). Draft Landscape of COVID-19 Candidate Vaccines.

9. Pfizer (2020). "Pfizer and BioNTech Achieve First Authorization in the World for a Vaccine to Combat COVID-19." Pfizer https://www.pfizer.com/news/pressrelease/press-release-detail/pfizer-and-biontech-achievefirst-authorization-world.

10. Hershberger Andy (2020). "Moderna Says Research Shows Its COVID-19 Vaccine Is Highly Effective with Few Side Effects." WMUR. https://www. wmur.com/article/moderna-covid-vaccine-updatedecember-9-2020/34918985.

11. Mahase Elisabeth (2020a). "Covid-19: Moderna Vaccine Is Nearly 95\% Effective, Trial Involving High Risk and Elderly People Shows.” BMJ, 371: m4471.

12. Knoll Maria Deloria, Chizoba Wonodi (2020). "OxfordAstraZeneca COVID-19 Vaccine Efficacy." The Lancet.

13. Foley Katherine Ellen (2020) "The Countries That Have Already Ordered Enough Vaccines for Their Entire Population." Quartz. https://qz.com/1937072/thecountries-that-have-already-ordered-enough-covid-19vaccines/.

14. GAVI (2020). "COVAX Explained." https://www.gavi. org/vaccineswork/covax-explained.

15. Xinhuanet (2020). "Sri Lanka in Talks with COVAX to Purchase COVID-19 Vaccines." Xinhuanet. http:/www. xinhuanet.com/english/2020-11/26/c_139545074.htm.

16. WHO (2020b). Pandemic Fatigue - Reinvigorating the Public to Prevent COVID-19. Policy Framework for Supporting Pandemic Prevention and Management. Copenhagen 2020. Licence: CC BY-NC-SA 3.0 IGO. Copenhagen, Denmark: WHO Regional Office for Europe.

17. Rachel Cassidy, Neha S Singh, Pierre-Raphaël Schiratti, Agnes Semwanga, Peter Binyaruka, et al. (2019). "Mathematical Modelling for Health Systems Research: A Systematic Review of System Dynamics and Agent-Based Models." BMC Health Services Research, 19: 845.

18. Kucharski Adam J, Petra Klepac, Andrew JK Conlan, Stephen M Kissler, Maria L Tang, et al. (2020). "Effectiveness of Isolation, Testing, Contact Tracing, and Physical Distancing on Reducing Transmission of SARSCoV-2 in Different Settings: A Mathematical Modelling Study." The Lancet Infectious Diseases, 20: 1151-1160.

19. Pearson Carl AB, Cari Van Schalkwyk, Anna M Foss, Kathleen M O'Reilly, SACEMA Modelling, et al. (2020). "Projected Early Spread of COVID-19 in Africa through 1 June 2020.” Eurosurveillance, 25: 2000543.

20. Wijesekara, N. W. A. N. Y., H. D. B. Herath, K. A. L. C. Kodithuwakku, H. M. M. N. K. Herath, B. A. M. P. Bulathsinghala, and C. C. Magedaragamage. 2020. "How
Would Widespread Community Transmission of Covid-19 in Sri Lanka Look like? A Population-Based Prediction." doi: 10.21203/rs.3.rs-101037/v1.

21. Wijesekara, N. W. A. N. Y., H. D. B. Herath, K. A. L. C. Kodithuwakku, Nayomi Herath, and B. A. M. P. Bulathsinghe. 2020. "COVID-19 Case Prediction and Outbreak Control of Navy Cluster in Sri Lanka: Effectiveness of SIR Model." doi: 10.21203/rs.3.rs-70722/ v1.

22. Davies Nicholas G, Petra Klepac, Yang Liu, Kiesha Prem, Mark Jit, et al. (2020). "Age-Dependent Effects in the Transmission and Control of COVID-19 Epidemics." Nature Medicine, 26: 1205-1211.

23. Davies NG, PS Wickramaratna, Samuel Clifford, Adam J Kucharski, Amy Glimma, et al. (2020). "COVID-19 Transmission Model (Beta Version)." CMMID Repository. https://cmmid.github.io/visualisations/covidtransmission-model-beta.

24. Godio Alberto, Francesca Pace, Andrea Vergnano (2020). "SEIR Modeling of the Italian Epidemic of SARS-CoV-2 Using Computational Swarm Intelligence." International Journal of Environmental Research and Public Health 17.

25. Mossong Joël, Niel Hens, Mark Jit, Philippe Beutels, Kari Auranen, et al. (2008). "Social Contacts and Mixing Patterns Relevant to the Spread of Infectious Diseases." PLOS Medicine, 5: e74.

26. Prem Kiesha, Alex R Cook, Mark Jit (2017). "Projecting Social Contact Matrices in 152 Countries Using Contact Surveys and Demographic Data." PLOS Computational Biology, 13: e1005697.

27. Epidemiology Unit (2020). “Epidemiology Unit.” http:// epid.gov.lk/web/index.php?lang=en.

28. Ministry of Health (2020) Instructions for Selected Public Activities/ Work Settings for the Prevention and Control of COVID-19 and General Guidance for the Public on Covid-19 Prevention.

29. WHO (2020e). WHO SAGE ROADMAP FOR PRIORITIZING USES OF COVID-19 VACCINES IN THE CONTEXT OF LIMITED SUPPLY - Version 1.1.

30. Kretzschmar Mirjam (2020). "Disease Modeling for Public Health: Added Value, Challenges, and Institutional Constraints." Journal of Public Health Policy, 41: 39-51.

Copyright: (C2021 NWANY Wijesekara. This is an open-access article distributed under the terms of the Creative Commons Attribution License, which permits unrestricted use, distribution, and reproduction in anymedium, provided the original author and source are credited. 